\title{
Design, Development and Evaluation of Instant Release Oral Thin Films of Flunarizine
}

\author{
Asfiya Fatima ${ }^{1}$, Mamatha Tirunagari2*, Divya Theja Chilekampalli² \\ ${ }^{1}$ Department of Pharmaceutics, Sultan-ul-Uloom College of Pharmacy, Road No: 3, Banjara Hills, Hyderabad, Telangana State, India \\ 2 Department of Pharmaceutics, Sarojini Naidu Vanita Pharmacy Maha Vidyalaya, Tarnaka, Secunderabd. Telangana State, India. \\ *Corresponding author's E-mail: tmamathasnvpmv@gmail.com
}

Received: 21-08-2021; Revised: 24-10-2021; Accepted: 03-11-2021; Published on: 15-11-2021.

\section{ABSTRACT}

The main objective of the present study was to prepare and evaluate the instant release oral thin films of Flunarizine, in order to enhance the bioavailability of the drug and to provide rapid onset of action thereby improving patient compliance. The instant release oral thin films of Flunarizine were prepared by solvent casting method using film forming polymer like Hydroxypropyl Methylcellulose E-15. The film was evaluated for various physicochemical parameters that include thickness, weight variation, folding endurance, tensile strength, drug content and in vitro drug release studies. No differences were observed in in vitro dissolution of drug from the formulated film F1-F9 as the film instantly gets wet by dissolution medium. The drug release for F5 formulations was about $98.1 \%$. The accelerated stability studies for the optimized film formulations F5 were performed that indicates that the formulated instant release oral thin films were unaffected after initial and 3 months storage under accelerated conditions.

Keywords: Oral film, Flunarizine, Instant release, Disintegration test.

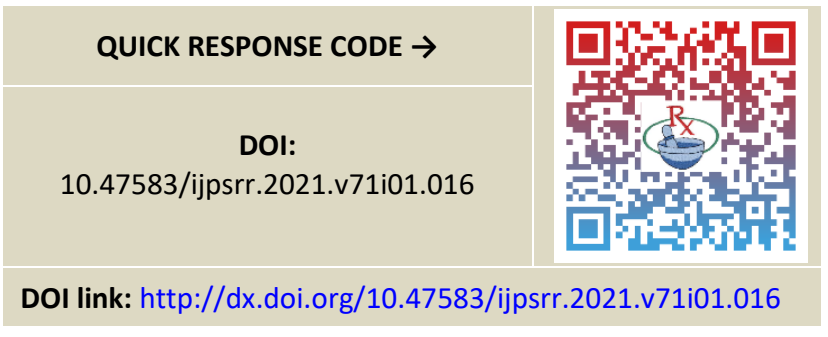

\section{INTRODUCTION}

T

he innovation of oral fast dissolving tablets has led to overcome the limitations of oral route of administration, which was introduced in $19^{\text {th }}$ century has led to the development of oral fast dissolving films. ${ }^{1-2}$ Fast dissolving films was a new approach for geriatric, dysphasic, pediatric and those patients who experience difficulty in swallowing oral formulations, where they disintegrate and quickly dissolve in oral cavity. ${ }^{3}$ The design of oral thin film is similar to postage stamp in size, shape and thickness, helps in easy administration of drug inside of cheek (buccal) and sublingually, as it is highly vascularized bypasses the first pass metabolism making more bio available medication. ${ }^{4}$

Flunarizine, calcium antagonist principally used in the treatment of migraine that is helpful in reducing the frequency of seizures. It is a selective class IV calcium antagonist that possesses calmodulin binding properties and also $\mathrm{H} 1$ blocking action. ${ }^{5}$ Migraine is a chronic disorder characterized by recurrent moderate to severe headaches. Development of Flunarizine oral thin films lead to overcome the inconvenience caused by Flunarizine tablets as they are convenient, shows fast action and compatible to patient's usage.

\section{MATERIALS AND METHODS}

\section{Materials}

Flunarizine was obtained as a gift sample from Hetero Pharma labs, Hyderabad, India, Hydroxy propyl methyl cellulose, Propylene glycol, Mannitol and Citric acid are obtained from SD Fine Chemicals Ltd., Mumbai, India, Aspartame and Ethanol from Research Lab Fine Chem Industries Ltd., Mumbai, India. All the chemicals used were of analytical grade.

\section{Methods}

\section{Calibration curve of Flunarizine}

Flunarizine was dissolved in $\mathrm{pH} 6.8$ phosphate buffer to get $100 \mu \mathrm{g} / \mathrm{ml}$ solution. Serial dilutions were made to get 2 $\mu \mathrm{g} / \mathrm{ml}, 4 \mu \mathrm{g} / \mathrm{ml}, 6 \mu \mathrm{g} / \mathrm{ml}, 8 \mu \mathrm{g} / \mathrm{ml}, 10 \mu \mathrm{g} / \mathrm{ml}$ of the final solution. The absorbance was measured at $256 \mathrm{~nm}$ by using UV spectrophotometer.

\section{Drug-polymer compatibility studies}

Drug polymer compatibility studies were carried out using Fourier Transform Infrared Spectrophotometer (FT-IR) (Shimadzu \& Perkin Elmer Instruments, USA). The FT-IR absorption spectra of Flunarizine and Flunarizine with polymers (1:1 ratio) was conducted by $\mathrm{KBr}$ disc method in the range of $4000-400 \mathrm{~cm}^{-1}$. The spectrum was studied for specific peaks of the drug and polymer.

\section{Calculation of area of film containing single dose of drug Flunarizine}

The dose of Flunarizine is $5 \mathrm{mg}$. Therefore, the amount of the Flunarizine drug required in the films is $5 \mathrm{mg}$.

Diameter of glass ring $=5.9 \mathrm{~cm}$ 
Radius $=$ Diameter $/ 2=5.9 / 2=2.95 \mathrm{~cm}$

As the dose is $5 \mathrm{mg}$ and cutting the pieces in no. of 2.25 $\mathrm{cm}^{2}$ films which are present in the whole ring $=27.3 / 2.25$ $=12.1$

Each film contains $5 \mathrm{mg}$ of the Flunarizine.

12.1 no. of films contain how much amount of drug? = 12.1 $\mathrm{X} 5=60.5 \mathrm{mg}$

The amount of drug added during preparation is equal to $60.5 \mathrm{mg}$, which is meant to be poured into one glass ring of diameter $5.9 \mathrm{~cm}$.

Therefore, the amount of Flunarizine in each film is $5 \mathrm{mg}$

\section{Development of formulation:}

\section{General considerations for formulation}

A distinctive composition of oral instant release thin film includes:

Active ingredients $(5-30 \% \mathrm{~W} / \mathrm{W})$, Polymer $(40 \% \mathrm{~W} / \mathrm{W})$, Plasticizer (5-20\% W/W), Sweetening agent (2-6\% W/W), Surfactant (q.s.), Saliva stimulating agent (3-6\% W/W), Colors, Fillers, Flavors (q.s). Potent and small molecular weight drugs are very good candidates for development of fast dissolving oral films formulation. ${ }^{6}$

\section{Preparation of blank films for preliminary screening of components}

Selection of a polymer based on its nature and concentration are important considerations for successful development of fast dissolving film. HPMC E-15 was used as a film former for the present research. Blank formulations were prepared by measuring different composition of polymer (200, 300, 400 and $500 \mathrm{mg}$ ) and dissolved in a suitable measured solvent. The polymer is soaked in solvent for a half an hour to obtain a homogeneous solution. The homogeneous solution is casted on a glass plate and allowed to dry at room temperature for $24 \mathrm{hr}$ or dry in a hot air oven at $45^{\circ} \mathrm{C}$ for 2 $\mathrm{hr}^{7}$ The precise volume of polymer solution is chosen on the basis of the thickness, clearance. The films obtained were evaluated for desirable properties like surface appearance, film clarity, film thickness, folding endurance and stickiness.

\section{Method of preparation of drug (Flunarizine) loaded oral thin films}

The oral thin films are prepared by solvent casting method. Polymer solution was prepared by dissolving weighed quantity of polymer (HPMC E-15) in required quantity of ethanol, soaked for half an hour to swell. Polymeric solution is then agitated for half-an-hour on a magnetic stirrer to obtain a uniform dispersion. Flunarizine is added to the polymer solution with continuous stirring for 5-10 minutes. Aspartame, Mannitol, Citric acid and Propylene glycol were added with remaining quantity of ethanol to the drug polymer solution and mixed for half an hour. The solution was then kept aside in undisturbed condition for the removal of air bubbles. The bubble-free solution was casted in $27.3 \mathrm{~cm}^{2}$ region containing the glass ring on the platform. The films are either dried for $24 \mathrm{hr}$ at room temperature or put under $45^{\circ} \mathrm{C}$ for $2 \mathrm{hr}$ in a hot air oven. The films were then carefully removed and imperfections were found. For further evaluation, films that were transparent and bubble free were chosen. The $2.25 \mathrm{~cm}^{2}$ films (1.25 X 1.25) were cut, draped in aluminum foil and then placed in desiccator.

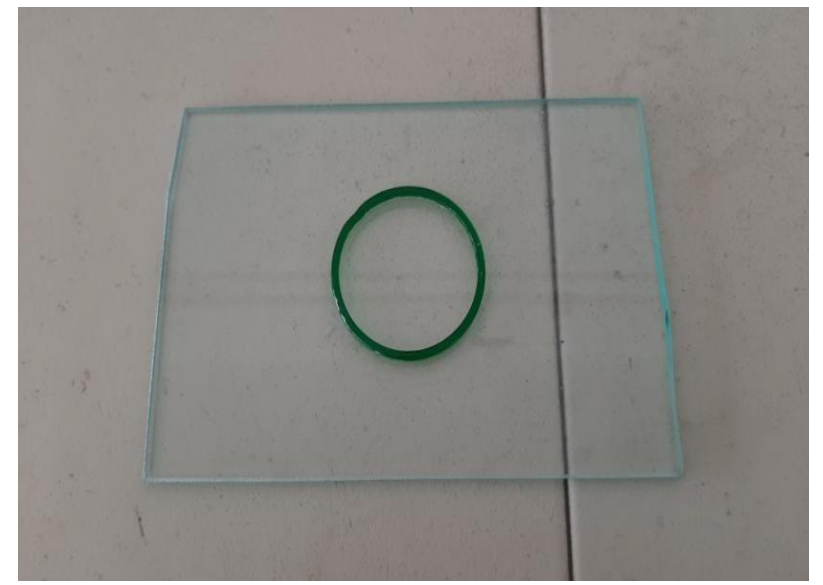

Figure 1: Rectangular shape thick glass slide with glass ring

Table 1: Composition of various oral thin film formulations of Flunarizine

\begin{tabular}{|c|c|c|c|c|c|c|c|c|c|c|}
\hline S.No & Components (mg/film) & F1 & F2 & F3 & F4 & F5 & F6 & F7 & F8 & F9 \\
\hline 1. & Drug (Flunarizine)* & 5 & 5 & 5 & 5 & 5 & 5 & 5 & 5 & 5 \\
\hline 2. & Polymer (HPMC E-15)* & 100 & 200 & 300 & 400 & 500 & 600 & 700 & 800 & 900 \\
\hline 3. & Sweetener (Aspartame)* & 25 & 25 & 25 & 25 & 25 & 25 & 25 & 25 & 25 \\
\hline 4. & Sweetener (Mannitol)* & 25 & 25 & 25 & 25 & 25 & 25 & 25 & 25 & 25 \\
\hline 5. & Plasticizer (Propylene glycol) ** (ml) & 0.15 & 0.15 & 0.15 & 0.15 & 0.15 & 0.15 & 0.15 & 0.15 & 0.15 \\
\hline 6. & Solvent (ethanol)** & Q.S. & Q.S & Q.S & Q.S & Q.S & Q.S & Q.S & Q.S & Q.S \\
\hline 7. & Saliva stimulating agent (citric acid)* & 5 & 5 & 5 & 5 & 5 & 5 & 5 & 5 & 5 \\
\hline
\end{tabular}




\section{Evaluation of instant release oral thin films}

\section{Morphological properties}

Instant release oral thin films were inspected physically for their transparency and air bubble. ${ }^{8}$ Each film was checked properly for its appearance, thickness, shape and size.

\section{Thickness of film}

Uniformity in thickness of the film is directly related to the accuracy of dose in the film. ${ }^{9}$ The thickness of the film was measured by micrometer at three different places and average of three values are calculated.

\section{Weight Variation}

From each film formulation three films of $2.25 \mathrm{~cm}^{2}$ size were cut at random. Individually films were weighed on electronic balance and the mean weight for every batch was calculated. ${ }^{5}$

\section{Folding Endurance}

This test ensures the tensile strength of the film and was checked by visual inspection. This was measured by repeatedly folding. The number of times the film is folded without breaking at the same place gives the folding endurance value. ${ }^{10}$

\section{Surface $\mathrm{pH}$}

The surface $\mathrm{pH}$ of the film was determined, since an acidic or alkaline $\mathrm{pH}$ may cause irritation. The $\mathrm{pH}$ of the film is calculated by moistening the film with $0.5 \mathrm{ml}$ distilled water, kept for $1 \mathrm{hr}$. The $\mathrm{pH}$ was measured by bringing $\mathrm{pH}$ electrode in make contact with surface of the film and allow it equilibrate for 1 minute. The averages of three values were determined. ${ }^{11}$

\section{Drug content uniformity}

Content uniformity is determined by estimating the content of the drug in individual films. Limit regarding to content uniformity is $85-115 \%$.

This is calculated by dissolving known weight of film in 100 $\mathrm{ml}$ of simulated saliva of $\mathrm{pH} 6.8$ for $30 \mathrm{~min}$ by continuous shaking. Then, spectrophotometrically, the concentration of the drug was analyzed at $\lambda \max 256 \mathrm{~nm}$. On average, five films have been taken. The concentration was measured with the normal calibration curve of Flunarizine.

\section{In vitro Disintegration method}

The disintegration time is the time when the film starts to disintegrate or break. This was determined visually by placing the oral film into the petridish containing $25 \mathrm{ml}$ of pH 6.8 phosphate buffer with swirling for every 10 sec. $^{12}$

\section{In vitro Dissolution test}

The dissolution test was performed by USP type II paddle dissolution apparatus. Drug loaded films (5 mg) was cut into $2.25 \mathrm{~cm}^{2}$ and placed in dissolution media consisting of $900 \mathrm{ml}$ freshly deionized simulated saliva of $\mathrm{pH} 6.8$ at $37 \pm$ $1^{\circ} \mathrm{C}$ stirred at $75 \mathrm{rpm}$. At predetermined intervals $5 \mathrm{ml}$ of sample were withdrawn and replaced with fresh medium. Blank film solution is used as blank while measuring absorbance. The solution is filtered using Whatmann filter paper, diluted suitably and the absorbance was measured at $256 \mathrm{~nm}$ by UV spectrophotometer. ${ }^{13}$

\section{Stability studies}

Instant release oral thin films of formulation F5 were placed at stability testing conditions of temperature $40 \pm$ $2^{\circ} \mathrm{C}$ and relative humidity of $75 \pm 5 \%$. Initial and third month study was carried out for the films. Films were wrapped in butter paper along with aluminum foil and then placed in an aluminum pouch which is heat sealed at the end. These instant release oral thin films were evaluated for their appearance, disintegration test, and in vitro dissolution test after storage of the films.

\section{RESULTS AND DISCUSSION}

In this study an attempt has been made to formulate and evaluate instant release oral thin films of Flunarizine.

\section{Calibration curve of Flunarizine}

The calibration curve of Flunarizine has a regression coefficient of 0.9983 and is shown in figure 2.

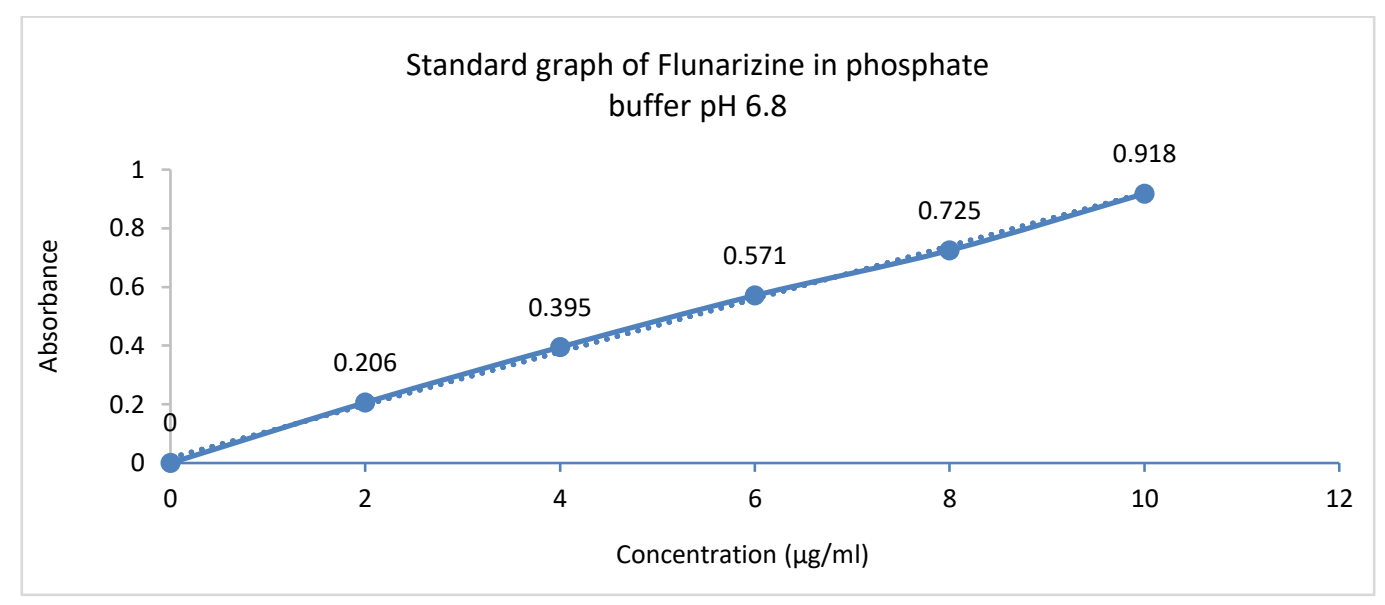

Figure 2: Standard graph of Flunarizine in phosphate buffer $\mathrm{pH} 6.8$ 


\section{Drug-polymer compatibility studies}

The peaks that are specific to the drug are observed both in pure drug and mixture FTIR spectra. Hence it was confirmed that drug and excipients are compatible. FTIR spectra of mixture is shown in figure 3.

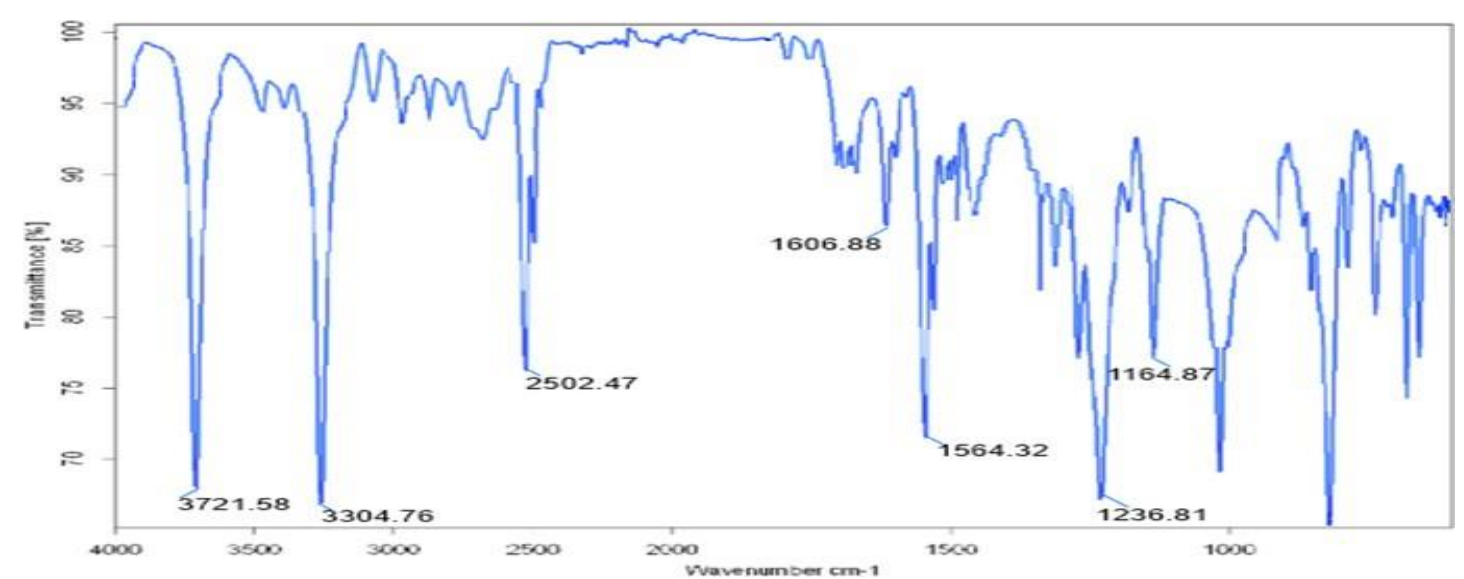

Figure 3: FTIR of Pure drug + excipients

\section{Evaluation test for instant release oral thin film formulations}

\section{Morphological properties}

The discovery is normal by visual examination of films and by touch and even feel, it clarified that the oral thin films are automatically released and have a smooth and elegant surface, i.e. they have a transparent, smooth surface, figure 4.

\section{Thickness of the films}

The thickness of oral thin films was observed to be between $0.11 \mathrm{~mm}$ to $0.20 \mathrm{~mm}$. The thickness was increased as the polymer quantity is more from formulation F1 to F9. These thickness values are depicted in table 2.

\section{Folding Endurance}

The folding endurance is found to be between 6 to 21 and is shown in table 2 . The films were found to be flexible.

\section{Surface $\mathrm{pH}$ value}

The surface $\mathrm{pH}$ value of instant release oral thin films is found to be in the range of 6.5-6.8 which is similar to oral cavity $\mathrm{pH}$.

\section{Drug content uniformity}

The drug content uniformity is performed by taking three instant release oral thin films in each formulation trial and the average drug content was calculated. The results of average drug content of all the films were summarized in table 2. All formulations drug content was found to be uniform hence it was confirmed that the method of preparation is most suitable.

\section{In vitro disintegration test}

The disintegration time of the prepared instant release oral thin films were in the range of $15 \mathrm{sec}$ to $35 \mathrm{sec}$. The results of average disintegration time of all the films were summarized in the table 2 . The least disintegration time is found to be for formulation F5 compared to other formulations. All the formulations disintegration time was found to be below one minute, indicating the correct formulation of all films.

Table 2: Evaluation data for instant release oral thin films of Flunarizine

\begin{tabular}{|c|c|c|c|c|c|c|}
\hline $\begin{array}{c}\text { Formulation } \\
\text { Code }\end{array}$ & Appearance & $\begin{array}{c}\text { Folding } \\
\text { Endurance }\end{array}$ & $\begin{array}{c}\text { Thickness } \\
\text { (mm) }\end{array}$ & Surface pH & $\begin{array}{l}\text { \% Drug } \\
\text { Content }\end{array}$ & $\begin{array}{l}\text { Disintegration } \\
\text { time (sec) }\end{array}$ \\
\hline $\mathrm{F} 1$ & Film is thick and not clear & 12 & 0.11 & 6.8 & 94 & 29 \\
\hline $\mathrm{F} 2$ & Film is smooth and clear & 15 & 0.13 & 6.6 & 95 & 25 \\
\hline F3 & Film is smooth and clear & 17 & 0.15 & 6.6 & 93 & 23 \\
\hline F4 & Film is clear but not have strength & 06 & 0.16 & 6.6 & 95 & 28 \\
\hline F5 & Film is smooth and clear & 21 & 0.16 & 6.5 & 98 & 15 \\
\hline F6 & Film does not have strength & 12 & 0.17 & 6.7 & 96 & 21 \\
\hline F7 & Film is clear but thick & 14 & 0.18 & 6.6 & 94 & 24 \\
\hline F8 & Film is clear but thick & 08 & 0.19 & 6.8 & 91 & 35 \\
\hline F9 & Film is smooth and clear, thick & 13 & 0.20 & 6.6 & 93 & 30 \\
\hline
\end{tabular}



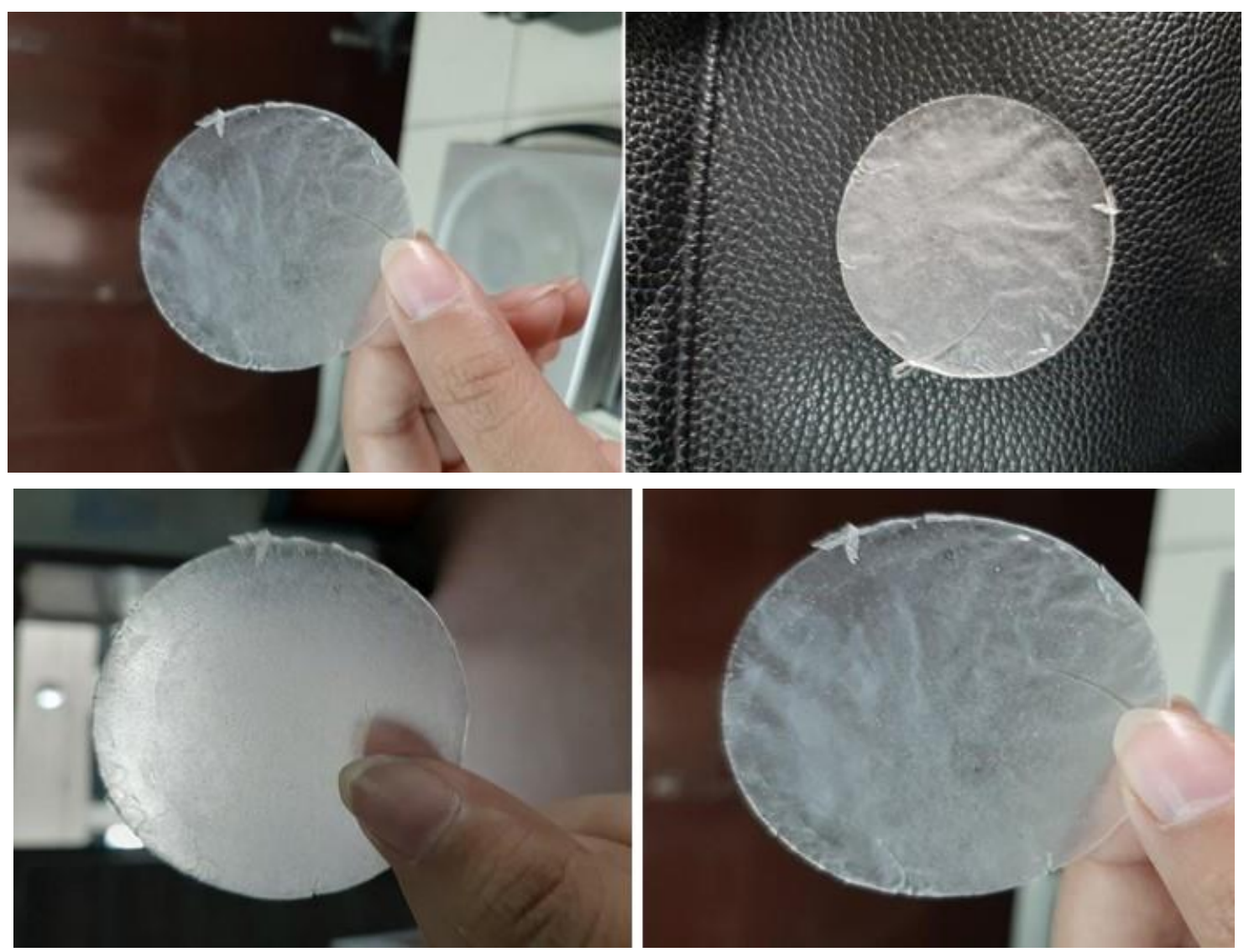

Figure 4: Prepared oral thin films

\section{In vitro dissolution studies}

The in vitro dissolution results were presented in table 3. In all the formulations more than 80 percent drug release was observed within 30 minutes. Compared to all formulations, in formulation F5, more than 90 percent of the drug release is observed in 10 minutes. As the disintegration time is also less for this formulation it was selected as best formulation among all and stability test was conducted for the same.

Table 3: In vitro drug release studies from F1 to F9

\begin{tabular}{|c|c|c|c|c|c|c|c|c|c|}
\hline \multirow{2}{*}{ Time (min) } & \multicolumn{8}{|c|}{ Cumulative percentage of drug release } \\
\hline $\mathbf{5}$ & F1 & F2 & F3 & F4 & F5 & F6 & F7 & F8 & F9 \\
\hline 10 & 42.15 & 48.10 & 62.21 & 68.35 & 85.41 & 79.10 & 80.21 & 74.62 & 51.95 \\
\hline 15 & 58.45 & 62.19 & 75.28 & 74.76 & 93.24 & 84.76 & 88.82 & 79.72 & 59.14 \\
\hline 20 & 79.72 & 73.76 & 86.76 & 84.49 & 95.29 & 91.19 & 91.17 & 83.25 & 74.86 \\
\hline 30 & 84.61 & 82.42 & 93.65 & 92.36 & 97.38 & 92.82 & 92.25 & 80.46 & 81.26 \\
\hline
\end{tabular}

\section{Stability studies}

Stability studies for the optimized film formulation F5 was performed at $40 \pm 2^{\circ} \mathrm{C} / 75 \pm 5 \% \mathrm{RH}$. The films were evaluated for appearance, disintegration time, percent drug release and results are shown in table 4. After stability testing not much difference is observed in appearance, disintegration time and percent drug release hence it was confirmed that the F5 formulation is stable.

Table 4: Stability studies of F5 formulation at $40 \pm 2^{\circ} \mathrm{C} / 75 \pm 5 \% \mathrm{RH}$

\begin{tabular}{|c|c|c|c|c|}
\hline S. No. & Time & Appearance & Disintegration time (sec) & $\begin{array}{c}\text { Cumulative percentage } \\
\text { drug release }\end{array}$ \\
\hline 1 & Initial (0 month) & Transparent and acceptable & 16.5 & 95.6 \\
\hline 2 & 3 months & Transparent and acceptable & 21 & 97.1 \\
\hline
\end{tabular}




\section{CONCLUSION}

The instant release oral thin films of Flunarizine were formulated by solvent casting method. Drug excipient compatibility studies determine that drug and excipient are compatible to each other. HPMC E-15 polymer was selected and different concentrations of formulation were formulated from F1 to F9 and assessed for various evaluation parameters. The films were thin and as the concentration increases the thickness also increases. All the films prepared were found to be flexible and transparent. Disintegration time was less for formulation F5. In vitro dissolution tests for formulations F1 to F9 were performed by USP type II paddle dissolution apparatus and the results revealed that the formulation F5 shows high dissolution profile and also the drug content was $98 \%$. The accelerated stability studies for the optimized film F5 formulations were performed and were unaffected after initial and 3 months storage under accelerated conditions.

\section{REFERENCES}

1. Arun Arya, Amrish Chandra, Vijay Sharma, Kamla Pathak., Fast dissolving oral films: An innovative drug delivery system and dosage form, Int. J. Chem. Tech. Res., 2010; 2(1): 576583.

2. Riffat Latif, Muhammad Ashfaq., Formulation Development and Evaluation of Fast Dissolving Oral Films of Alprazolam, J. Adv. Med. Pharm. Sci., 2019; 21(4): 1-20.

3. Ali MS, Vijendar C, Sudheer Kumar D and Krishnaveni J., Formulation and Evaluation of Fast Dissolving Oral Films of Diazepam, J. Pharmacovigil., 2016; 4(3):51-59.

4. Rathi Jagdish, Sahu Rahul Kumar, Solanki Praveen, Kotwar Ramesh, Khan Nadeem, Mathur Rahul., Formulation and Evaluation of Fast Dissolving Oral Film of Prochlorparazine dimaliate, J. Med. Pharm. Allied Sci., 2016; 456-471.
5. Petra O, Thomas K, Kai-Thomas K, Karin K., Oral, quickly disintegrating film, which cannot spit out, for an antiemetic or ant migraine agent. US 2008/0213343 A1 2008: 1-6.

6. Bhyan B, Jangra $S$, Kaur $M$, Singh $H_{\text {., }}$ Orally fast dissolving films: Innovations in formulation and technology, Int. J. Pharm. Sci. Rev. Res., 2011; 9(2): 50-57.

7. Rajni Bala, Shailesh Sharma, IKGPTU., Formulation Optimization and Evaluation of Fast dissolving film of Aprepitant by using design of experiment, Bull. Fac. Pharm. Cairo Univ., 2018; 56(2): 159-168.

8. Sandeep DJ, Rahul NK, Chetan MJ, Bharat WT, Vijay RP., Formulation and Evaluation of Fast Dissolving Oral film of Levocetirizine dihydrochlorid, Int. J. Pharm. Pharm. Sci., 2012; 4(1): 337-341.

9. Pravin Kumar Sharma, Pankaj Kumar Sharma, Gajanan ND, Birendra Shrivastava., Formulation and Evaluation of Mouth Dissolving Film of Tadalafil, J. Drug Deliv. Ther., 2017; 7(7): 52-55.

10. Namrata R, Tahir N, Ankit M, Neelesh M, Vishakha C, Neelima S., Formulation and Evaluation of Fast Dissolving Oral Films of an Anti-Migrain Drug (Zolmitriptan), J. Drug Deliv. Ther., 2019; 9(2-A): 59-61.

11. Alka Tomar, Kiran Sharma, Nitesh Chauhan S, Ashu Mittal, Umakant Bajaj., Formulation and Evaluation of Fast Dissolving Oral Film of Dicyclomine as potential route of Buccal Delivery, Int. J. Drug Dev. \& Res., 2012; 4(2): 408-417.

12. Mamatha T, Syed Ahmed, Anitha N., Development, Formulation and Evaluation of Atomoxetine Oral Films, Int. J. Drug Dev. \& Res., 2014; 6(2): 46-51.

13. Aditya Singh, Vaseem A. Ansari, Md Faheem Haider, Farogh Ahsan, Tariq Mahmood, Shubhrat Maheshwari, Ritesh Kumar Tiwari., Oral Fast Dissolving Film: The Avant-garde Avenue for oral Consignment Modus Operandi, Res. J. Pharm. Tech., 2021; 14(4): 2145-2152.

Source of Support: The author(s) received no financial support for the research, authorship, and/or publication of this article.

Conflict of Interest: The author(s) declared no potential conflicts of interest with respect to the research, authorship, and/or publication of this article.

For any question relates to this article, please reach us at: editor@globalresearchonline.net New manuscripts for publication can be submitted at: submit@globalresearchonline.net and submit_ijpsrr@rediffmail.com 